
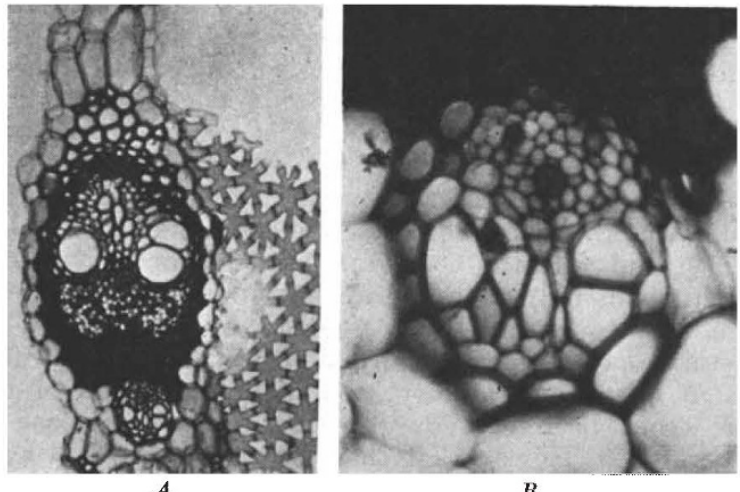

Fig. 1. $A$, Transverse section of longitudinal vascular bundle in leaf of Thurnia sphaerocephala (Rudge) Hook.f. showing an inverted vascular bundie on the lower side of the selerenchyma sheath $(\times c .52)$;
$B$, inverted vascular bundle from $A$, at higher magnification $(\times \quad$ c. 262)

Metcalf $\Theta^{2}$ has recently directed attention to the very wide range of leaf structure which occurs in the Cyper. aceae and other monocotyledons, but so far the type of vascular organization here described for the Thurniaceae has not been seen elsewhere. It should be noted that the vascular arrangement in the leaf of Thurnia differs from that in the equitant leaf of Iris spp. where the vascular bundles of opposite pairs have their xylem poles facing towards one another ${ }^{3}$. It also differs from the type of structure found in Lepidosperma (Cyperaceao), which recalls that of an equitant leaf of an Iris, and from Lagenocarpus (Cyperaceae), where some of the vascular bundles are in pairs but with the xylem pole of each bundle facing towards the adaxial surface of the leaf (Metcalfe, loc. cit., Fig. 11).

It is difficult to explain in morphological, phylogenetic or physiological terms how the type of vascular structure found in the leaf of Thurnia has been evolved. This problem must be viewed against the broad background of the range of structure in the monocotyledons and it is hoped that the continuing researches into the anatomy of the monocotyledons at this laboratory will throw further light on this problem.

Jodrell Laboratory,

David F. Cuther

Royal Botanic Gardens, Kew.

'Solereder, H., and Meyer, F. J., Systematische Anatomie der Monokotyledonen, 4, Farinosae (Berlin, 1929).

${ }^{2}$ Metcalfe, C. R., Advances in Botanical Research, 1 (Academic Press, London and New York, 1903).

${ }^{3}$ Arber, A., Monocotyledons (Cambridge Botanical Handbooks, Cambridge, 1925).

\section{Morphometry of Wool Fibres}

THE occurrence of irregularities in tho shape of the crosssection of wool fibres along their length is woll known. The variations are in the area and ellipticity of the crosssoction as well as tho inclination of the major axis of the ellipse. Efforts have been made to take account of these irregularities in the intorpretation of mechanical tests on fibres both theorotically ${ }^{1-3}$ and experimentally ${ }^{4}$. Disagreement and high variance of results exist in published determination $s^{5-7}$ of fibre breaking stress and its dependence on average fibre diameter, breed and age of sheep. Some recent oxperiments ${ }^{8}$ basing the breaking stress on the minimum instead of the mean cross-sectional area within the test longth showed a lower variance and indicated the importance of oxamining the area variations in greater detail as suggosted long ago by Rossouw ${ }^{8}$. This has been done with a newly developed fibre rotator and a much finer structure of irregularity has been found than might have been expocted.

Apparent diamoters of the fibres were measured on a fibre rotator of which a detailed description will be given elsewhere designed to fit a projection Lanameter microscope. The fibres were measured while immersed in paraffin oil after conditioning to an atmosphere of 65 per cent relative humidity, and $20^{\circ} \mathrm{C}$. The fibre was rotated through $180^{\circ}$ in increments of $18^{\circ}$ (one turn of the rotator handwheel) and at each setting the diameter and the angle of rotation were recorded. From these readings the lengths of the semi-major axis $a$ and of the semi-minor axis $b$ of the elliptical fibre cross-section were decided. The crosssection area $\pi a b$, the ellipticity $a / b$, and the angular orientation of the major axis $\theta$ were calculated and aro shown for a typical highly uniform Merino fibre in Fig. 1. Readings were taken at axial intervals of $0.5 \mathrm{~mm}$ along a 2 -cm length of fibre, and at $0.040 \mathrm{~mm}(40 \mu)$ for two of the $0.5-\mathrm{mm}$ intervals selected at random and shown by the vertical dotted lines in Fig. 1. It will be seen that there are four places where the fibre thickness $\pi a b$ departs by more than 10 per cent from its mean value in the very short length of $0.5 \mathrm{~mm}$ and that a change of 24 per cent in thickness occurs in $40 \mu$, a distance of twice the fibro diameter. Some of the fluctuation in cross-sectional area is due to the rise and fall of the scales along the fibre surface. However, close examination (of this source of fluctuation) showed a contribution of less than 2 per cent from this cause. The results of measurements on a fow Corriedale and Lincoln fibres were similar to those for the Merino shown in Fig. 1, except that for coarser fibres the axial rate of change of $\theta$ was slower.
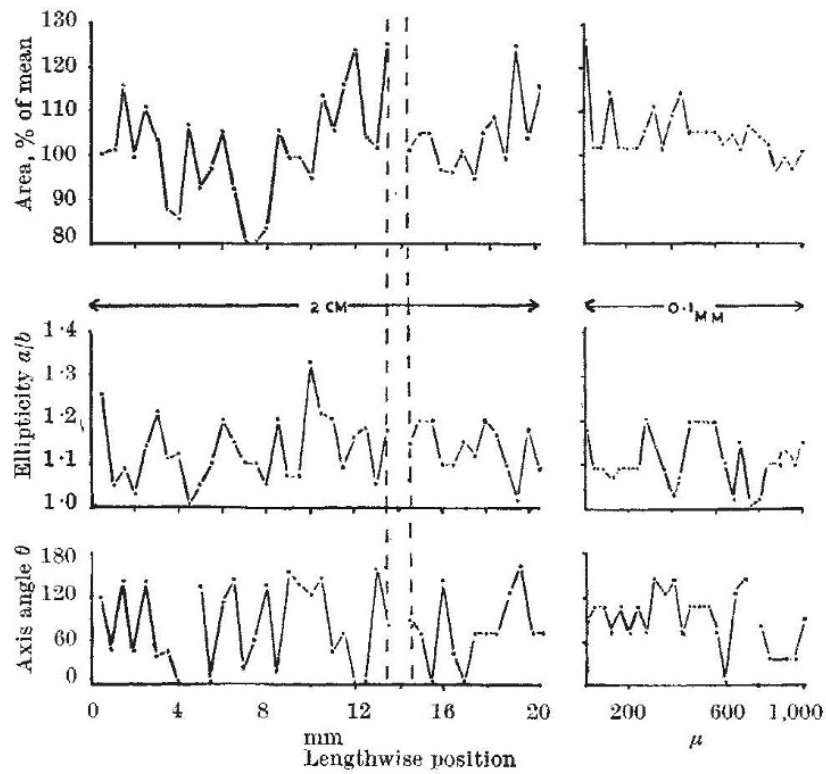

Fig. 1

The rapid changes of cross-sectional area observed are contrary to the assumption that the thickness of a fibre varies only slowly along the axis postulated by Peirce ${ }^{1}$ and Zhurek ${ }^{2}$ and assumed, at least implicitly, in most experimental work on the mechanical properties of fibres.

\section{J. F. P. JAMES}

C.S.I.R.O. Wool Research Laboratories, Division of Textile Physics, Ryde, Sydnoy.

${ }^{1}$ Peirce, F. 'I., J. Text. Inst., 17, T, 355 (1926).

2 Zhurek, V., Telhnologiya Textil'Noi Promyshlennosti, No. 6 (19), 녀 (1960).

"Kenny, P., and Chaikin, M., J. Text. Inst., 50, T, 18 (1959).

${ }^{4}$ Burgmann, V. D., Text. Res. J., 29, 901 (1959).

${ }^{3}$ Thorsen, W. J., Text. Res. J., 28, 185 (1958).

- O'Connell, I. A., and Lundgren, II. P., Text. Res. J., 24, 677 (1954).

'Lecomte, J., Mazingue, G.. and Van Overbèke, M., Bull. Inst. Text. (France), No. 69, 8 (1957).

${ }^{8}$ Roberts, N, F., James, J. F. P., and Burgmann, V. D., J. Text. Inst. 51, T, 935 (1960).

- Rossouw, 9. D., J. Text. Inst., 24, T, 874 (1931). 